\title{
$\widehat{A}$ Madridge \\ madridge Journal of Vaccines \\ nterconnecting Scientific World
}

Short Communication Article

Open Access

\section{HPV Vaccine Scenario in India - A Short Report}

\author{
Akanksha Rathi ${ }^{1 \star}$ and Satya Vir Singh ${ }^{2}$ \\ ${ }^{1}$ Assistant Professor, Department of Community Medicine, Dr Baba Saheb Ambedkar Medical College E Hospital, New Delhi, India \\ ${ }^{2}$ Director Professor E Head, Department of Community Medicine, Dr Baba Saheb Ambedkar Medical College E Hospital, New Delhi, India
}

\section{Article Info}

\section{*Corresponding author:}

Akanksha Rathi

Assistant Professor

Department of Community Medicine

Dr Baba Saheb Ambedkar Medical College \& Hospital

New Delhi, India

E-mail: akanksharathi.dr@gmail.com

Received: September 18, 2018

Accepted: September 24, 2018

Published: September 29, 2018

Citation: Rathi A, Singh SV. HPV Vaccine Scenario in India - A Short Report. Madridge $J$ Vaccines. 2018; 2(1): 62-63.

doi: $10.18689 / \mathrm{mjv}-1000113$

Copyright: (c) 2018 The Author(s). This work is licensed under a Creative Commons Attribution 4.0 International License, which permits unrestricted use, distribution, and reproduction in any medium, provided the original work is properly cited.

Published by Madridge Publishers

\begin{abstract}
Cervical Cancer is the third most common cancer in women worldwide with estimated 529000 new cases and 275000 deaths globally in 2008. Indian contribution to cervical cancer cases is $25.4 \%$ and contribution to the mortality due to this disease is $26.5 \%$. The most important risk factor for development of cervical cancer is persistent infection by a high-risk subset of human papilloma virus (HPV) which is the most common viral sexually transmitted infection. India is in a unique position to benefit from the introduction of HPV vaccination in national immunization schedule, but many factors play a role in the implementation of this futuristic immunization drive.
\end{abstract}

Keywords: Cervical Cancer; HPV; Vaccine.

\section{Introduction}

Cancer is perhaps the most progressive and devastating disease posing a threat of mortality to the entire world despite significant advances in medical technology for its diagnosis and treatment [1]. It is estimated that by the year 2020 there will be almost 20 million new cases [1]. The most common cancers among females are cervix, breast, ovary, oesophagus and mouth. Of this, cervical cancer is the second most common cancer among women worldwide after breast cancer. Cervical Cancer is the third most common cancer in women worldwide with estimated 529000 new cases and 275000 deaths globally in 2008 [2]. Indian contribution to cervical cancer cases is $25.4 \%$ and contribution to the mortality due to this disease is $26.5 \%$ [3]. The most important risk factor for development of cervical cancer is persistent infection by a high-risk subset of human papilloma virus (HPV) which is the most common viral sexually transmitted infection [4]. The advent of HPV vaccination has advanced hopes that the dream of eradication of cervical cancer might be possible in future. Prophylactic vaccines for cervical cancer target HPV 16 and 18, the most common oncogenic types of HPV responsible for cervical cancer. Since cervical screening only detects precancerous and cancerous changes after they have occurred, HPV vaccination is primary prevention.

India is in a unique position to benefit from the introduction of HPV vaccination in national immunization schedule, but many factors play a role in the implementation of this futuristic immunization drive. A multi-centric study in India [5], has reported that genotypes 16 and 18 alone or in co-infection with each other were detected in $76.3 \%$ cases, this lays the basis of introduction of the vaccine in the country. Unlike other viral infections, where the natural infection will elicit a strong host immunogenic response, HPV infection leads to production of antibodies in only 50\% of those infected [6]. Further, these antibodies are not necessarily protective against re-infection by the same HPV type over time [7]. On the other hand, the vaccine-induced immunity is much stronger, long lasting, and includes partial cross-protection to non-vaccine-related serotypes [8]. Models predict that vaccination programmes for young adolescent females will substantially reduce the incidence of cervical cancers associated with 
vaccine-related HPV types if coverage is high (>70\%) and vaccine-induced protection lasts for $\geq 10$ years [7]. When we look at the cost of the vaccine, which is much higher than any vaccine in our current immunization schedule, a country like India which has many pressing health issues might want to defer the introduction of this vaccine. However, studies have shown that HPV vaccination may be cost-effective in lowincome and middle-income countries (where quality screening is not widespread) if the cost per vaccinated girl (including three doses of vaccine and programmatic costs) is < US $\$ 10$ 25 , which is substantially lower than current costs in highincome countries [9]. Another study done in India in Punjab state reported that there is a $90 \%$ probability for the vaccination strategy to be cost-effective in Punjab state at a willingness-to-pay threshold of INR 10,000, which is less than one-tenth of the per capita gross domestic product [10].

Despite of the promising results of vaccination, there are a few roadblocks. Firstly, the side effects of the vaccine, such as autoimmune neurologic demyelination (paralysis, blindness, and death), albeit rare, have been associated with Gardasil due to higher antigenic protein load [11-12]. Safety of these vaccines when given in combination with other vaccines is not proven. Secondly, though cervical cancer may be a major cause of cancer in females, but cancer registries show that incidence rates are significantly declining (noted between years 1982 and 2005) [13]. There are certain sociocultural issues associated with the HPV vaccine because it targets a sexually transmitted infection (STI) and primarily targets female adolescents and young adults, and this is another roadblock that limits the acceptance of this vaccine by parents of beneficiaries. The question can often arise that whether we need a vaccination or a comprehensive screening programme for cervical cancer as our first priority. Although both strategies can go side by side, the money constraint and the low GDP of India, the third roadblock, are the prohibitory factors for simultaneous implementation.

WHO recommends that routine HPV vaccination should be included in national immunization programmes, provided that prevention of cervical cancer or other HPV-related diseases, or both, constitutes a public health priority; vaccine introduction is programmatically feasible; financially sustainable; and is cost effectiveness in the country [7]. Time and again, it has been proven that HPV vaccines are safe and efficacious against typespecific HPV-induced anogenital warts, precancerous lesions, and cervical cancer and the vaccines are most effective when given before the onset of sexual activity. Though, there is a need for new clinical trials and follow up of old trials on issues like efficacy, safety, duration of protection, need for booster dose, the current evidence supports the introduction of HPV vaccination as part of a coordinated strategy to prevent cervical cancer, and other HPV-related diseases. However, regionspecific guidelines should be based on cost-effectiveness and feasibility of implementing HPV vaccination as a part of national immunisation schedule, so the operational difficulties will be discovered only after the true implementation of HPV vaccination in India. We must remember that vaccination alone will not be successful unless it is coupled with education about healthy sexual behavior and information about the diagnosis and treatment of precancerous lesions and cancer. So, the government should run an effective Behavior Change Communication (BCC) program simultaneously with vaccination.

\section{References}

1. Senapathy JG, Umadevi P, Kannika PS. The present scenario of cervical cancer control and HPV epidemiology in India: an outline. Asian Pac J Cancer Prev. 2011; 12(5): 1107-15.

2. Mishra GA, Pimple SA, Shastri SS. An overview of prevention and early detection of cervical cancers. Indian J Med Paediatr Oncol. 2011; 32(3): 125-132. doi: 10.4103/0971-5851.92808

3. Nigam A, Saxena P, Acharya AS, Mishra A, Batra S. HPV Vaccination in India: Critical Appraisal. ISRN Obstet Gynecol. 2014; 2014: 5. doi: $10.1155 / 2014 / 394595$

4. Walboomers JM, Jacobs MV, Manos MM, et al. Human papillomavirus is a necessary cause of invasive cervical cancer worldwide. J Pathol. 1999; 189: 12-19.

5. Basu P, Roychowdhury S, Bafna UD, et al. Human papillomavirus genotype distribution in cervical cancer in India: results from a multi-center study. Asian Pac J Cancer Prev. 2009; 10(1): 27-34.

6. Carter JJ, Koutsky LA, Hughes JP, et al. Comparison of human papillomavirus types 16, 18, and 6 capsid antibody responses following incident infection. J Infect Dis. 2000; 181: 1911-9. doi: 10.1086/315498

7. Human papillomavirus vaccines. WHO position paper. Wkly Epidemiol Rec. 2009; 84(15): 118-31.

8. Pandhi D, Sonthalia S. Human papilloma virus vaccines: Current scenario. Indian J Sex Transm Dis AIDS. 2011; 32(2): 75-85. doi: 10.4103/25890557.85409

9. Goldie SJ, O'Shea M, Diaz M, Kim SY. Benefits, cost requirements and cost-effectiveness of the HPV 16, 18 vaccine for cervical cancer prevention in developing countries: policy implications. Reprod Health Matters. 2008; 16: 86-96. doi: 10.1016/S0968-8080(08)32409-4

10. Prinja S, Bahuguna P, Faujdar DS, et al. Cost-effectiveness of human papillomavirus vaccination for adolescent girls in Punjab state: Implications for India's universal immunization program. Cancer. 2017; 123(17): 32533260. doi: $10.1002 /$ cncr.30734

11. DiMario FJ, Hajjar M, Ciesielski TA. A 16-year-old girl with bilateral visual loss and left hemiparesis following an immunization against human papilloma virus. Journal of Child Neurology. 2010; 25(3): 321-327. doi: $10.1177 / 0883073809349322$

12. Sutton I, Lahoria $R$, Tan IL, Clouston $P$, Barnett MH. CNS demyelination and quadrivalent HPV vaccination. Multiple Sclerosis. 2009; 15(1): 116-119. doi: $0.1177 / 1352458508096868$

13. Dhillon PK, Yeole BB, Dikshit R, Kurkure AP, Bray F. Trends in breast, ovarian and cervical cancer incidence in Mumbai, India over a 30-year period, 1976-2005: an age-period-cohort analysis. Br J Cancer. 2011; 105(5): 723-730. doi: 10.1038/bjc.2011.301 